\section{International Scientific Journal Theoretical \& Applied Science}

p-ISSN: 2308-4944 (print) ｅ-ISSN: 2409-0085 (online)

Year: 2017 Issue: $07 \quad$ Volume: 51

Published: $30.07 .2017 \quad$ http://T-Science.org

SECTION 31. Economic research, finance, innovation, risk management.
Malahat Omar Panahaliyeva Associate Professor of the Department «World Economics and Marketing» of the Sumgayit State University

Shafiga Safar Mamedova Associate Professor of the Department «World Economics and Marketing» of the Sumgayit State University

Gyulnara Sabir Akhmedova Senior Lecturer of the Department «World Economics and Marketing» of the Sumgayit State University

Konul Vagif Shirvani Lecturer of the Department «World Economics and Marketing» of the Sumgayit State University,

Sumgayit, Azerbaijan Republic nauka-xxi@mail.ru

\title{
MODELING OF USE OF RESOURCES UNDER CONDITIONS OF IMPLEMENTATION OF STRATEGIC ROAD MAPS IN AZERBAIJAN
}

\footnotetext{
Abstract: The modeling of the use of resources in the context of the implementation of strategic road maps in Azerbaijan is studied in the article. The main problems and questions on effective use of the main resources - fuel and energy resources of the country are analyzed. The essence of the concept of resources and their role in the development of the national economy are revealed. The main sources and groups of fuel and energy resources, mechanisms and their regulation are considered. The priority directions for effective use of fuel and energy resources in Azerbaijan in modern conditions are determined.

A number of recommendations and proposals on modeling the use of resources in the implementation of strategic road maps in Azerbaijan are given at the end of the article.

Key words: Azerbaijan, economic resources, efficiency, use of resources, modeling of resource use, strategic road maps in Azerbaijan.

Language: Russian

Citation: Panahaliyeva MO, Mamedova SS, Akhmedova GS, Shirvani KV (2017) MODELING OF USE OF RESOURCES UNDER CONDITIONS OF IMPLEMENTATION OF STRATEGIC ROAD MAPS IN AZERBAIJAN. ISJ Theoretical \& Applied Science, 07 (51): 87-91.

Soi: http://s-o-i.org/1.1/TAS-07-51-15 Doi: crostef https://dx.doi.org/10.15863/TAS.2017.07.51.15

\section{МОДЕЛИРОВАНИЕ ИСПОЛЬЗОВАНИЯ РЕСУРСОВ В УСЛОВИЯХ РЕАЛИЗАЦИИ СТРАТЕГИЧЕСКИХ ДОРОЖНЫХ КАРТ В АЗЕРБАЙДЖАНЕ}

Аннотация: В статье исследовано моделирование использования ресурсов в условиях реализации стратегических дорожных карт в Азербайджане. Анализированы основные проблемы и вопросы по эффективному использованию главных ресурсов - топливно-энергетических ресурсов страны. Раскрыта сущиноть понятия ресурсов и их роль в развитии национальной экономики. Рассмотрены основные источники и группь топливно-энергетических ресурсов, механизмы и их регулирование. Определень приоритетные направления по эффективному использованию топливно-энергетических ресурсов в Азербайджане в современных условиях.

В коние статьи дан ряд рекомендаций и предложений по моделированию использования ресурсов $в$ условиях реализации стратегических дорожных карт в Азербайджане.

Ключевые слова: Азербайджан, экономические ресурсы, эффективность, использование ресурсов, моделирование использования ресурсов, стратегические дорожные карты в Азербайджане.
} 


\section{Introduction}

После восстановления независимости в Азербайджане один из главных вопросов и проблем по развитию национальной экономики было связанно с эффективностью использования национальных богатств и природных ресурсов страны на благо населения и обеспечения устойчивости развития общества и экономики страны. В Азербайджане главным источником природных богатств и полезных ископаемых является топливно-энергетические ресурсы, в том числе углеводородные ресурсы, которые выступают в качестве основных видов сырья промышленных продукций - нефти, газа, нефтехимии и прочее. В стране имеется достаточно разведанных и изученных залежей нефти и газа и других источников минеральных ресурсов, часть которых успешно осваивается с применением современных технологий и высоко инновационным оборудованием.

\section{Materials and Methods}

Отметим, что проблемы умелого и рационального использования народных богатств и природных ресурсов страны высоко оценены и отмечены ещё в трудах основоположников экономической теории. А.Смит отмечал важность рационального использования природных богатств на благо народов и развития экономики[1]. Кроме того, обоснована необходимость рационального использования природных богатств и ресурсного потенциала страны для развития производственного цикла. А.Маршал считал, что природные и экономические ресурсы должны быть основным компонентом развития производственных процессов и формирования источников национального дохода[2]. Азербайджан, долгие годы, находясь в составе бывшего СССР, был вынужден отдавать все доходы в общую казну союзного государства, и оставался в качестве производителя. Республика не имела права заниматься распределительными функциями ресурсов и сырьевых компонентов, с целью их переработки в национальных интересах и не учувствовал во внешне экономических связях с другими странами мира. Поэтому, в начале 1990x годов Азербайджану пришлось заново создавать и развивать национальную концепцию и стратегии по освоению национальных источников природных богатств и углеводородных залежей, одновременно обеспечить их переработку и самостоятельно выходить на мировые рынки. Необходимо было, да и нуждалось время для привлечения иностранных инвестиций в разработку и освоение основных нефтегазовых месторождений, и построить соответствующую инфраструктуру транспортировки нефтегазовых ресурсов на мировые рынки. За прошедшее время в стране проводились огромные работы и с реализацией «Нефтяной стратегии» Азербайджан стал одним из главных энергетических партнёров Европейского Союза и стал играть ведущую роль в реализации региональных и международных энергетических проектов в регионе с участием крупных нефтегазовых компаний мира (ВР и т.д.) и странами региона (Грузия, Турция и прочее). Однако в связи с ростом глобальных тенденций и прочих негативных последствий глобализации требуется разработка и осуществление максимально эффективных направлений и механизмов по переработке топливноэнергетических ресурсов в пользу расширения структуры национальной экономики и повышения её конкурентоспособности на мировых рынках. Дело в том, что страны мира упорно стараются и стремятся добиться новых источников природных запасов и энергетических ресурсов для моделирования развития своей национальной экономики[3]. С этой точки зрения, Азербайджану природа подарила богатые подземные и наземные ресурсы, в том числе самые ценные топливно-энергетические ресурсы - нефть и газ. В стране имеются многие виды полезных ископаемых, такие как титан, хромит, медь, кобальт, золото, серебро, известковые камни, травертин, мрамор, гипс, кварцевые пески и прочее[4]. Отметим, что в Азербайджане имеются мощные залежи бентонита и цеолитов. В целом в стране имеется свыше 550 залежей полезных ископаемых, и они взяты на учёт для освоения промышленным путём и созданы на базе перерабатывающих предприятий[5]. В Азербайджане имеется свыше 1000 залежей для организации развития промышленных сфер[6]. Известно, что в Азербайджане имеется разные виды углеводородных ресурсов и прочих природных богатств, которые позволяют интенсификации расширения перерабатывающей промышленности и снижения роли нефтяного сектора в экономике страны. Академик А.Надиров с группой учёных провели фундаментальные исследования по определению размера, объёма и мощности, а также по эффективному использованию природных ресурсов страны и рассмотрели моделирование максимально рационального использования топливно-энергетических ресурсов в нынешних условиях[7, с.9]. Проблемы эффективности и моделирование ресурсного потенциала страны были актуальными темами в трудах известных учёных современности Азербайджана. Академик 3.Самедзаде отмечает, господ щедро одарил Азербайджан природными богатствами, есть у нас и солидный производственный, научнотехнический, интеллектуальный, трудовой потенциал, страна, в которой мы живем, 
находится на стыке Востока и Запада, Европы и Азии, то есть на важнейшем геостратегической перекрестке. Располагая столь выгодными преимуществами, Азербайджан сегодня имеет и четкие приоритеты экономической стратегии, реализация которой позволит нашей республики добиться наивысших показателей экономического роста и качественного уровня развития[8, с.888]. В Азербайджане имеется благоприятные условия для развития предпринимательство и бизнеса по разработку, освоению и добычи природных ресурсов с дальнейшим созданием и развитием промышленных предприятий, в которую со свою очередь позволяет расширить сеть предприятий способных формировать добавочную стоимость для роста национальной экономики. Профессор А.Шакаралиев считает, что государство должен проводить активную экономическую политику по повышению эффективности переработки сырьевых ресурсов и создать более конкурентоспособные сети промышленных предприятий. Необходимо активно привлечь иностранные инвестиции и внедрение современных технологий по освоению и рациональному использованию природных богатств на благо населения страны[9]. Интересно, что по расчётам специалистов общая стоимость подтверждённых 28 залежей полезных ископаемых, которые считаются ценными для формирования промышленного запаса и развития промышленной деятельности оценивается на сумму 40 млрд. долл. США. Нынешние известные запасы нефти хватит на 70-100 лет, а запасы природного газа на 200 лет, однако в ближайшей перспективе ожидается утверждение и освоение новых перспективных нефтегазовых залежей. Профессор Э.Гаджизаде отмечает, что необходимо привлечь больше иностранных инвестиции на организацию перерабатывающих сетей нефтегазовых сырьевых ресурсов и производить сотни видов конкурентоспособных промышленной продукции[10, с.16]. Более того, требуется активное использование преимущественных факторов экономики Азербайджана по расширению высокотехнологичных перерабатывающих предприятий по повышении экспортного потенциала страны и тем самым создать условия для минимизации негативных последствий финансовых кризисов и снижения цен на нефть в мире, что отрицательно влияет на стабильность финансово-кредитного сектора страны и в целом на макроэкономическую и макрофинансовую стабильность. Профессор Ш.Алиев подчёркивает, что Азербайджан богат своими природными ресурсами и сможет, не только обеспечит себя основными видами энергоносителям, но и способен повысить объем экспорта этих ресурсов. Для этого, необходимо умело воспользоваться имеющегося ресурсного потенциала в стране[11, с.117]. В Азербайджане развернуто огромные работы по моделирование использование ресурсов в условиях реализации, истекающих задачей от стратегических целей дорожных карт, способствует по-новому оценить возможность и потенциал природных ресурсов и в целом ресурсного потенциала страны, в том числе топливно-энергетических ресурсов в условиях роста глобальных угроз и тенденций в мировых экономических процессах. Проблемы концептуального понимания эффективности использования ресурсов требует подойти основным источникам данного проблема в контексте обеспечения устойчивого развития национальной экономики. Кроме того, вопросы экономической безопасности страны обуславливает концептуального подхода по развитию топливно-энергетического комплекса и тем самым обеспечить рационального использования топливно-энергетических ресурсов[12]. Более того, проблемы концептуальности использования минеральных и энергетических ресурсов страны требует детального изучения каждого компонента организации сети перерабатывающих предприятий, и обеспечить изобилие конкурентоспособных продукций на рынке энергетических ресурсов. Необходимо учитывать основные сегменты и конъектуру рынка энергетических ресурсов[13]. Например, в Китае особое отношение использование ресурсов топливно энергетического комплекса заключается в том, что одним из обязательных условий является применение высокой технологии и инновационных функций. Аналогичный подход способствует повышению эффективности ресурсного потенциала, их моделированию и применению адекватного механизма управления энергетическими ресурсами[14]. Проводимые исследования и наличие современных подходов по эффективному использованию ресурсов в нынешних условиях позволяет определить основные направления и механизмы моделирования использования ресурсов (см. рисунок 1). 


\begin{tabular}{|c|c|c|c|c|c|c|}
\hline Impact Factor: & $\begin{array}{l}\text { ISRA (India) } \\
\text { ISI (Dubai, UAE } \\
\text { GIF (Australia) } \\
\text { JIF }\end{array}$ & $\begin{array}{l}=1.344 \\
=0.829 \\
=0.564 \\
=1.500\end{array}$ & $\begin{array}{l}\text { SIS (USA) } \\
\text { PИHЦ (Russia) } \\
\text { ESJI (KZ) } \\
\text { SJIF (Morocco) }\end{array}$ & $\begin{array}{l}=0.912 \\
=0.234 \\
=3.860 \\
=\mathbf{2 . 0 3 1}\end{array}$ & $\begin{array}{l}\text { ICV (Poland) } \\
\text { PIF (India) } \\
\text { IBI (India) }\end{array}$ & $\begin{array}{l}=6.630 \\
=1.940 \\
=4.260\end{array}$ \\
\hline
\end{tabular}

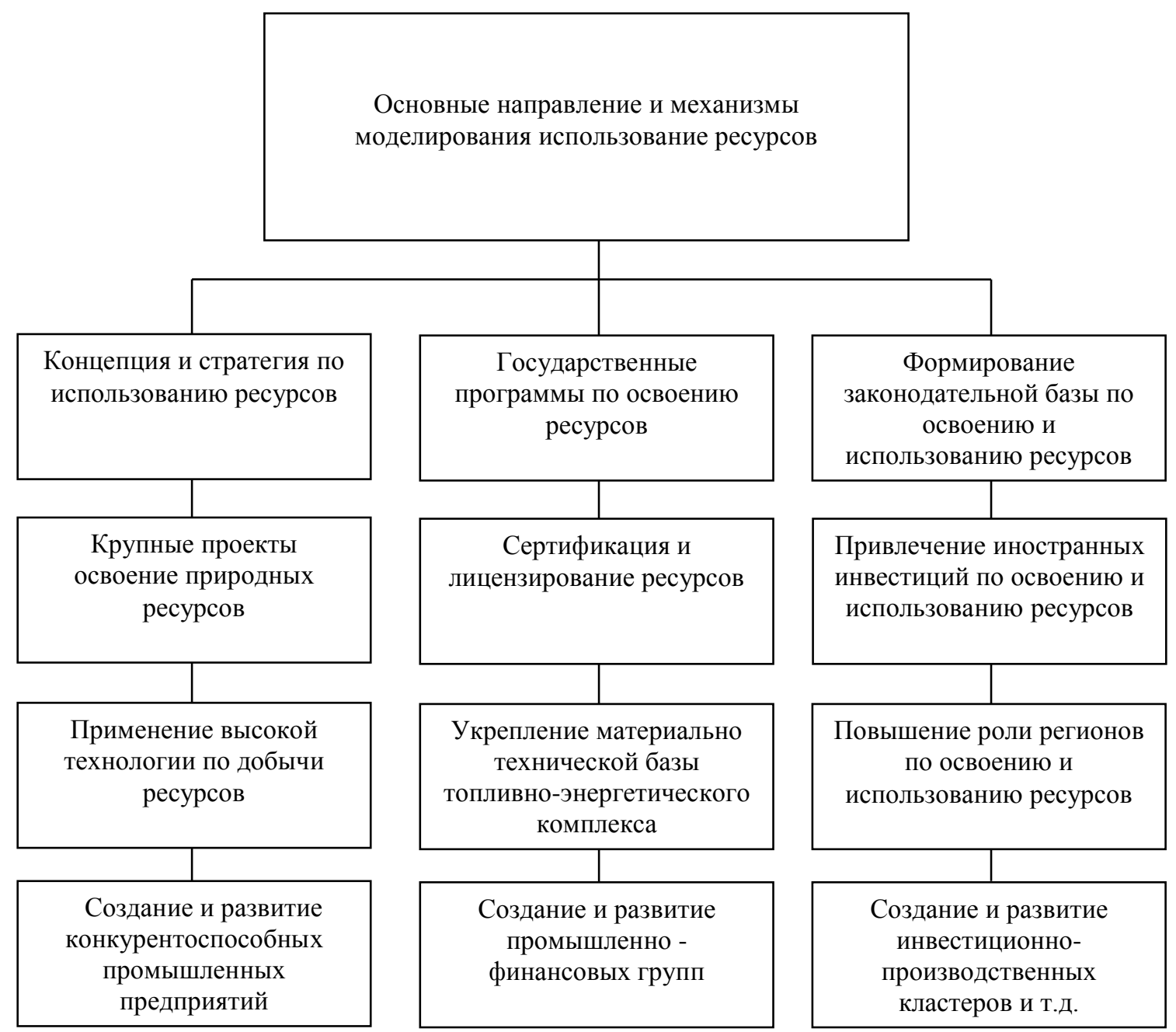

Рисунок 1 - Основные направление и механизмы моделирования использование ресурсов в современных условиях (разработано автором).

Анализ Рисунка 1 даёт возможность, отметить, что в числе главных направлений и механизмов моделирования использования ресурсов в современных условиях выходит в первую очередь разработка адекватной концепции и стратегии, а также государственная программа использования ресурсов, формирование законодательной базы, реализация крупных проектов с применением высоких технологий и создания конкурентоспособных промышленных предприятий, промышленнофинансовых групп, инвестиционнопроизводственных кластеров и прочее.

В Азербайджане, в последние годы, проводится последовательная государственная экономическая политика и в конкретные работы по совершенствованию механизмов и инструментарий моделирования использования ресурсов, созданию конкурентоспособных перерабатывающих предприятий и реализации стратегических целей по повышению эффективности ресурсного потенциала страны на благо населения и развития национальной экономики в условиях роста глобальных угроз. Bce эти намерения предусмотрены в стратегическом плане Министерства Энергетики Азербайджанской Республики на период 20152020 годов[15]. Более того, в стратегическом плане в ближайшей перспективе определены конкретные цели и стратегические задачи по повышению рациональности максимального использования ресурсного потенциала по схемам с получением добавочной стоимости и создания конкурентоспособных промышленных предприятий, новых рабочих мест и с выводом в эксплуатации высокотехнологичных установок и оборудований. В стратегической дорожной карте по перспективам национальной экономики и основным секторам экономики страны предусмотрена реализация множественных конкретных работ по интенсификации проводимых мероприятий с использованием ресурсного потенциала страны с учётом обеспечения устойчивости и роста национальной экономики в ближайшей и долгосрочной перспективе[16]. 


\begin{tabular}{|c|c|c|c|c|c|c|}
\hline Impact Factor: & $\begin{array}{l}\text { ISRA (India) } \\
\text { ISI (Dubai, UAE } \\
\text { GIF (Australia) } \\
\text { JIF }\end{array}$ & $\begin{array}{l}=1.344 \\
=0.829 \\
=0.564 \\
=1.500\end{array}$ & $\begin{array}{l}\text { SIS (USA) } \\
\text { PИНЦ (Russia) } \\
\text { ESJI (KZ) } \\
\text { SJIF (Morocco) }\end{array}$ & $\begin{array}{l}=0.912 \\
=0.234 \\
=3.860 \\
=\mathbf{2 . 0 3 1}\end{array}$ & $\begin{array}{l}\text { ICV (Poland) } \\
\text { PIF (India) } \\
\text { IBI (India) }\end{array}$ & $\begin{array}{l}=6.630 \\
=1.940 \\
=4.260\end{array}$ \\
\hline
\end{tabular}

\section{Conclusion}

Таким образом, предстоит сделать огромные работы по обновлению и осуществлению моделирования использования ресурсов в условиях реализации стратегических дорожных карт в Азербайджане, от которых зависит дальнейшее обеспечение конкурентоспособности национальной экономики и ускорение модернизации, отдельных её секторов. Поэтому, необходимо разработать и осуществить более продуктивные и многофункциональные механизмы использования ресурсного потенциала с учётом обеспечения их эффективности в процессах интенсификации, модернизация экономического развития страны на фоне роста глобальных экономических влияний, происходящих трансформаций экономических процессов и т.д.

\section{References:}

1. Smith, Adam. Wealth of Nations, edited by C. J. Bullock. Vol. X. (2001) The Harvard Classics. New York: P.F. Collier \& Son, 190914; Bartleby.com.

2. Alfred Marshall (1891) Principles of Economics, 1890-1891.

3. (2017) Rol' prirodnykh zapasov $\mathrm{v}$ razvitii mirovoy ekonomike. Available: http://www.kayzen.az. (Accessed: 10.07.2017).

4. (2017) Poleznyye iskopayemyye Azerbaydzhana. Available: http://www.kayzen.az. (Accessed: 10.07.2017).

5. (2017) Mesto i rol' gornodobyvayushchey promyshlennosti v ekonomike Azerbaydzhane. Available: http://www.stategiya.az. (Accessed: 10.07.2017).

6. (2000) Geology and mineral resources of Azerbaijan. New York.

7. Nadirov A., Muradov SH., Aleskerov A., Nuriyev A., Guseynov T. (2003) Ekonomika Azerbaydzhana. Baku, «Nauka», -344 p.

8. Samedzade Z.A. (2004) Etapy bol'shogo putiekonomika Azerbaydzhana za polveka, yeye novyye realii i perspektivy. Baku, Izdatel'skoPoligraficheskiy Tsentr «NURLAR», -936 p.

9. Shakaraliyev A.SH. (2009) Ekonomicheskaya politika gosudarstva: realii i perspektive (monografiya). Baku: «Ekonomicheskiy Universitet», $-416 \mathrm{p}$.
10. Gadzhizazhe E.M. (2003) Modernizatsiya ekonomicheskoy struktury neftyanoy khozyaystva. Baku, «Nauka», -512 p.

11. Aliyev SH.T. (2010) Vazhneyshiye determinanty ustoychivogo razvitiya ekonomiki Azerbydzhana. Baku: «Elm», $-196 \mathrm{p}$.

12. Fomenko O.V. (2000) Toplivnoenergeticheskiy kompleks Rossii $\mathrm{v}$ mirovoy politike: na primere deyatel'nosti rossiyskikh neftyanyy korporatsiy. Diss. kand. polit. nauk. Moscow, $-176 \mathrm{p}$.

13. Zhaboyedova Ye.A. (2003) Transformatsiya ekonomicheskikh otnosheniy rynka energeticheskikh resursov. Diss. kand. ekon. nauk. Irkutsk, $-208 \mathrm{p}$.

14. Bin' V. (2006) Sovershenstvovaniye ekonomicheskogo mekhanizma upravleniya energeticheskimi resursami Kitaya. Diss. kand. ekon. nauk. Sankt-Peterburg, -160 p.

15. (2014) Strategicheskiy plan Ministerstva Energetiki Azerbaydzhanskoy Respubliki na period 2015-2020-yye gody. Utverzhdeno prikazam №39 ot 5-go dekabrya 2014-go goda Ministra Energetiki Azerbaydzhanskoy Respubliki.

16. (2017) Strategicheskikh dorozhnykh kart po natsional'noy ekonomike i osnovnym sektoram ekonomiki. Utverzhdeno Ukaz Prezidenta Azerbaydzhanskoy Respubliki ot 6-go dekabrya 2017-go goda. 